\title{
Development and Validation of a Novel Particle Source for Nano-sized Test Aerosols
}

\author{
Christian Monsé $^{1 *}$, Christian Monz ${ }^{2}$, Burkhard Stahlmecke ${ }^{3}$, Birger Jettkant ${ }^{1}$, Jürgen Bünger ${ }^{1}$, \\ Thomas Brüning $^{1}$, Volker Neumann ${ }^{2}$, Dirk Dahmann ${ }^{2}$ \\ ${ }^{1}$ Institute for Prevention and Occupational Medicine of the German Social Accident Insurance, Institute of the Ruhr- \\ Universität Bochum (IPA), 44789 Bochum, Germany \\ ${ }^{2}$ Institute for the Research on Hazardous Substances (IGF), 44789 Bochum, Germany \\ ${ }^{3}$ Institute of Energy and Environmental Technology e.V. (IUTA), 47229 Duisburg, Germany
}

\begin{abstract}
In the EU, there is an increasing need for regulatory agencies to establish health-based threshold limits for airborne particles. A prerequisite for such projects is the validation and comparison of existing and newly developed particle analyzers. Corresponding proficiency tests have often been conducted with the help of inter-laboratory tests using test aerosols. Although test aerosols in the micro- and the nanoscale range were produced with different generator systems at the technical center of the Institute for the Research on Hazardous Substances (IGF) in Dortmund, a stable and reproducible method of producing a low number concentration for nano-sized particles was not achieved. Inspired by a method of monodisperse droplet generation, we coupled a flame generator with a droplet generator and examined the concentration and the diameter of the formed particles as a consequence of the precursor concentration and the droplet frequency. In addition, the reproducibility of the method was tested daily, and the nanoparticles were collected and characterized microscopically. Finally, the measurements of the particle size distribution were mathematically examined. The resulting fits enable the prediction of the median particle diameter as a function of the precursor concentration and the frequency of the droplets. Overall, the performed experiments confirm that this system meets all the requirements with regard to a low number concentration and long-term stability and reproducibility and should therefore be suitable for further inter-laboratory round robin tests.
\end{abstract}

Keywords: Nanoparticles; Test aerosol; Flame generator; Droplet generator.

\section{INTRODUCTION}

Test aerosols necessary to conduct proficiency tests were generated using different generator systems at the technical center of the Institute for the Research on Hazardous Substances (IGF) in Dortmund (Dahmann et al., 2001; Asbach et al., 2009; Fonseca et al., 2016). The generated particles covered the spectrum from micro- to nanoscale ranges, with the former being successfully produced using an atomizer or compressed air atomization. Thus far, in order to produce particles in the nanoscale range, a flame generator that produces nanoparticles from sprayed aqueous or solvent-containing precursor solutions by pyrolysis with a hydrogen-oxygen flame has been used (Monsé et al., 2014). For example, materials such as zinc oxide (Monsé et al.,

\footnotetext{
* Corresponding author.

Tel.: +49 (0)234 302-4521; Fax: +49 (0)234 302-4505

E-mail address: monse@ipa-dguv.de
}

2018), titanium dioxide, silicon dioxide, copper (II) oxide and lead oxide (Giesen et al., 2016a; Raschig et al., 2016) have all been investigated. Due to the large number of droplets produced by the nebulization of precursor solutions with an integrated two-substance nozzle, the concentration of primary particles produced by the pyrolysis process was very high - in the range of $10^{10}-10^{11} \mathrm{P} \mathrm{cm}^{-3}$-leading to the rapid formation of aggregates and agglomerates. The resulting particle diameters depended on the volume flow at which the particle stream was diluted, and only very high flow volumes (about $5000 \mathrm{~m}^{3} \mathrm{~h}^{-1}$ ) resulted in primary particles where aggregate and agglomerate formation was no longer observed (Monsé et al., 2014).

Numerous inter-laboratory comparisons indicated that some particle analyzers were not able to cope with the high number concentration because the detection limit was significantly exceeded (Asbach et al., 2012; Kaminski et al., 2013). When using the flame generator, only a small decrease in number concentration was observed when more dilute precursor solutions were used. The authors showed that the precursor concentration only had a small influence 
on particle concentrations by using fixed diluting volume flows; whereas, the median diameter of the generated particles strongly increased (Monsé et al., 2014). Pyrolysis of more concentrated precursor solutions generated primary particles that rapidly agglomerated and aggregated, yielding increased median diameter. Further experiments were performed with a split valve with the aim to dilute only a fraction of the particles in order to reduce the number concentration. However, it was found that both the desired long-term stability of the dilution and the reproducibility of the particle number concentration could not be achieved. The dilution ratios were increased (up to 1:1000) and subject to strong variations due to the adjustment accuracy of the split valve. Therefore, the aim of this work was to develop a generator system that stably and reproducibly produces a range of smaller particle number concentrations compared to the existing flame generator.

The Institute for Occupational Safety and Health (IFA) has established a process for the production of reference materials for sulfuric and phosphoric acid-doped filter media using a droplet generator from microdrop Technologies (Giesen et al., 2016b; Raschig et al., 2016) that is based on piezo-driven inkjet printing technology. The authors used highly diluted aqueous solutions of the acids, thus using $37 \mathrm{~mm}$-diameter cellulose nitrate filters with an $\mathrm{x}, \mathrm{y}$ manipulator following a specific pattern. The technology used made it possible to produce different filter series of a few hundred individual filters each. Quality checks of the amount of acid applied on the filters resulted in standard deviations of $<1 \%$. In addition, day-to-day compliance was excellent, within the margin of error in the scale of what is observed on a single day.

Various working groups have coupled this microdrop generator system with inductively coupled plasma mass spectrometry (ICP-MS) systems, explored the properties of such systems, and compared them with other sample delivery systems, such as spray chambers or nebulizers (Groh et al., 2009; Gschwind et al., 2011; Franze et al., 2012; Borovinskaya et al., 2013). It could be shown that the droplet generator is able to generate monodisperse droplets from the sample matrices to be examined, which could be introduced into the plasma with an efficiency that is close to $100 \%$. The deviation of the droplet diameter was $<1 \%$.

There is already a large community dealing with a socalled "flame spray pyrolysis (FSP)" process that was systematically investigated by Mädler et al. (2002) and Tani et al. (2002). These devices generate a fine jet spray of a metal salt solution which is pyrolyzed in a flame to form particles. The particle concentrations and the median particle diameters can be widely adjusted by varying the gas flow, the concentration of the metal salt precursor, or the flow of the atomizing gas. Additional information is available from Teoh et al. (2010), who published a comprehensive review about the preparation of various oxide and nonoxide ceramic particles via FSP. Some working groups modified the synthesis route to generate particles by using electrosprays in order to inject a precursor solution into a flame (Geier and Parker, 2013). There are also other studies working on spray pyrolysis, i.e., with different generator types combined with tube furnaces (ionized source gases: Adachi et al., 2003; ultrasonic atomizer: Pingali et al., 2005; gas phase via bubbler: Miettinen et al., 2009). Wang et al. (2013) used as a source of precursor a solution of titanium tetrachloride and water that was sprayed as a nano-aerosol by an atomizer into a microwave plasma reactor for rapidly ( $<1$ second) synthesizing mainly anatasestructure titanium dioxide powders. In one of the latest studies by Abram et al. (2018), a flame synthesis approach is described for producing metal oxide nanoparticles. It is based on a novel micro-jet atomization technique, which generates solution aerosol droplets in the sub-micron range with a mean diameter of $200 \mathrm{~nm}$. There, the droplet size distribution of the aerosol droplets has been measured and its effect has been discussed.

Inspired by the reproducible method of droplet generation which is based on piezo-driven inkjet printing technology, we have coupled our existing flame generator with the droplet generator. The feasibility of this complete system was tested, with most of the experimental time invested into finding a suitable precursor solution. Subsequently, the concentration and particle diameters that resulted as a function of the different starting concentrations and applied droplet frequency were examined. Reproducibility was tested daily, and the nanoparticles were collected and characterized microscopically. Finally, the measured particle size distributions were mathematically examined. The resulting fits allowed the prediction of the median particle diameter as a function of the precursor concentrations used and the frequency of the droplet generator.

\section{METHODS}

\section{Nanoparticle Source}

As illustrated in Fig. 1, we used a combination of a nanoparticle generator (1) (Model FG 3, MoTec Konzepte, Germany) to pyrolyze the micro-sized droplets (7) generated with a piezo-electric droplet generator (2) (Model MD-K-140-020, microdrop Technologies, Germany). The generation process and the diameter of the micro-sized droplets (7) could be monitored with a camera (3) and a strobe diode. The camera was mounted on a $\mathrm{x}, \mathrm{y}, \mathrm{z}-\mathrm{manipulator}(4)$ in order to bring the aerosol droplets (7) into focus. The use of a protective tube (5) allowed an undisturbed free fall of the aerosol droplets (7) into the flame cone. The distance from the output of the generator (2) to the flame was chosen to be $7 \mathrm{~cm}$, a relatively large distance in order to prevent the waste heat of the flame adversely affecting the droplet-generating process. The use of the Venturi tube (6) allowed the droplets (7) to be horizontally deflected along the flame cone while being pyrolyzed at the same time. In addition, it was ensured that no turbulent flow occurred to prevent the droplets (7) from hitting any walls. The generated nanoparticles (8) exited at the end of the Venturi tube (6) and entered the atmosphere of our exposure laboratory (Monsé et al., 2012).

The complete experimental setup was installed on a table inside the laboratory, and a ceiling fan was used to homogenize the freshly generated nanoparticles. Preliminary 


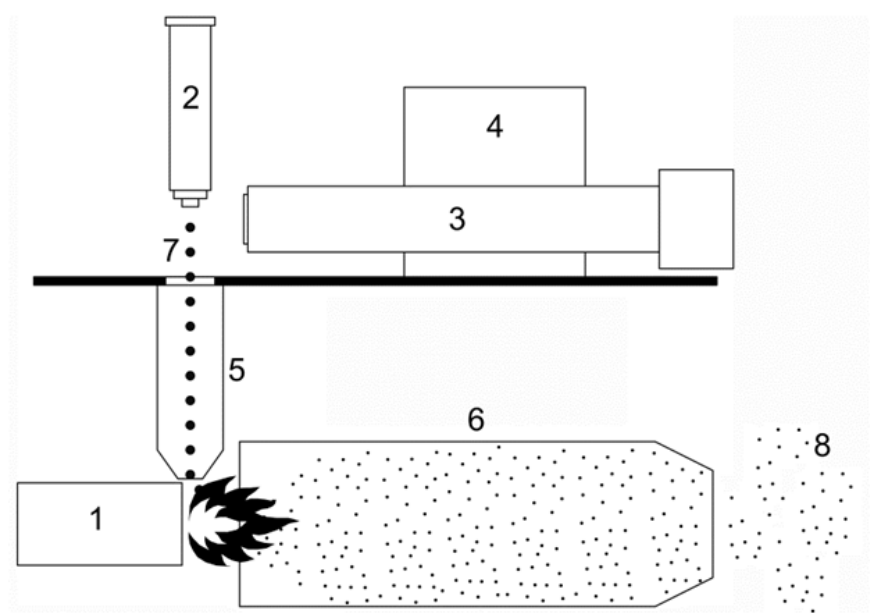

Fig. 1. Schematic view of the nanoparticle source. 1: Flame generator, 2: piezo-electric droplet generator, 3: camera, 4: x,y,z-manipulator, 5: protective tube, 6: Venturi tube, 7: micro-sized droplets, 8: nanoparticles.

tests with zinc oxide nanoparticles showed that particle atmospheres could be evenly distributed (Pillar et al., 2016). The air exchange rate was set to 12 per hour $\left(360 \mathrm{~m}^{3} \mathrm{~h}^{-1}\right)$ with a room temperature of $23^{\circ} \mathrm{C}$ and a relative humidity of $50 \%$.

The following settings were used for the flame generator (1) during all experiments: the hydrogen volumetric flow rate was set to $3.0 \mathrm{~L} \mathrm{~min}^{-1}$ and the oxygen flow to $1.5 \mathrm{~L} \mathrm{~min}^{-1}$. Argon was switched off. The atomizing gas was compressed air with an inlet pressure of 150 mbar.

Three precursor solutions were prepared by dissolving $0.5,1.0$, and $1.5 \mathrm{~g}$ copper (II) nitrate hemi(pentahydrate) $\left(\mathrm{Cu}\left(\mathrm{NO}_{3}\right)_{2} \cdot 2.5 \mathrm{H}_{2} \mathrm{O}\right.$, purity: 98-102\%; Alfa Aesar $\mathrm{GmbH}$ \& Co. KG, Germany) to a total volume of $10 \mathrm{~mL}$ ethylene glycol (purity > 99.5\%; Sigma Aldrich Chemie $\mathrm{GmbH}$, Germany). Each mixture was placed in an ultrasonic bath for 15 minutes at room temperature to accelerate the dissolution process. The solutions are indefinitely stable at room temperature.

The droplet generator is based on piezo-driven inkjet printing technology. The integrated piezo actuator induces a shockwave into the fluid contained in the head, which causes a droplet to be emitted from the nozzle. The inner nozzle diameter was $50 \mu \mathrm{m}$ and was heated to $50^{\circ} \mathrm{C}$ to compensate temperature fluctuations in the surrounding air and waste heat from the flame generator. The shockwave could be adjusted by means of a control software (Autodrop, release 7 , microdrop Technologies, Germany). Changing the pulse width to within the range of 28-39 $\mu$ s and the pulse height to within the range of 99-113 V yielded aerosol droplets with a constant diameter of $50.2 \mu \mathrm{m}$. The frequency of shockwaves per second was set to $10,25,50$, $100,250,500$, and $1000 \mathrm{~Hz}$.

\section{Measurement and Sampler Devices}

A Scanning Mobility Particle Sizer (SMPS; Model 3080, TSI Inc., USA) equipped with a nano differential mobility analyzer and a butanol condensation particle counter (Model 3776, TSI Inc.) measured the particle size distributions in the exposure unit. The number concentration and size distributions were determined every 5 minutes. The SMPS device was outside the exposure lab. The atmospheres to be investigated were continuously passed through a $3 \mathrm{~m}$-long stainless steel tube (diameter: 0.5 inch) with a volumetric flow rate of $5 \mathrm{~L} \mathrm{~min}^{-1}$ to minimize diffusion losses. A T-piece placed directly at the inlet of the device was used to draw in the particles with a volumetric flow rate of $0.9 \mathrm{~L} \mathrm{~min}^{-1}$. Sheath air volume flow was set to $9 \mathrm{~L} \mathrm{~min}^{-1}$.

An electrostatic Nanometer Aerosol Sampler (NAS; Model 3089, TSI Inc; Dixkens and Fissan, 1999) was used to sample particles onto TEM-grids for consecutive SEM analyses. The NAS was used with a custom-built unipolar corona charger upstream of the inlet area. The charger used a sharp tungsten needle, around which a corona was formed upon applying a DC voltage of $+4.0 \mathrm{kV}$. The corona generated ions that positively charge the particles to achieve nearly $100 \%$ particle sampling efficiency in the electric field of the NAS (operated at $-10 \mathrm{kV}$ ). The sampling times were set to 1 or 2 minutes with an internal airflow of $1.0 \mathrm{~L} \mathrm{~min}^{-1}$.

The TEM-grids were analyzed in a JEOL $7500 \mathrm{~F}$ scanning electron microscope operated at $25 \mathrm{kV}$ acceleration voltage with a nominal resolution of $2 \mathrm{~nm}$. Besides the standard SEM mode, a scanning transmission electron detector (Generation 5 STEM detector, KE Developments) operated in dark field mode was additionally used to obtain images of the deposited particles due to the low particle size. Using the STEM dark field mode, the images are obtained from scattered electrons passing the sample, thus allowing a good distinction between materials of different atomic number. Scattering of the electrons predominantly occurs at the copper particles that have a much higher atomic number compared to the carbon layer of the TEM-grid. The particles appear as a white spot on the images both for the SEM and STEM mode.

Mathematical Examination of Particle Size Distributions

All measured particle size distributions were fitted to a log-normal distribution $f(d)$ as a model size distribution. The normalized log-normal distribution $f(d)$ as a function of mobility particle diameter, $d$, is expressed in two 
parameters, $\mu$ and $\sigma(\sigma>0)$, related to the production process and is symmetrical around the geometric mean on a log diameter scale.

$$
f(d)=\frac{1}{\sqrt{2 \pi} \sigma d} \exp \left(-\frac{(\ln (d)-\mu)^{2}}{2 \sigma^{2}}\right)
$$

Many parameters can then be directly derived analytically from these fitted probability density functions (PDF). Its global maximum is reached at the diameter $d_{0}=\exp \left(\mu-\sigma^{2}\right)$ and the expected value can be calculated as:

$$
d=\exp \left(\mu+\frac{\sigma^{2}}{2}\right)
$$

All log-normal distributions were fitted through data points using MATLAB (release R2014a, MathWorks Inc., USA). All statistical analyses were done with Statistica 14 (Statsoft, Germany). The quality of all fits of the model function is given by the coefficient of determination, denoted as $\mathrm{R}^{2}$. All fitted log-normal distribution describes the measured particle size distribution in detail with $0.98<$ $\mathrm{R}^{2}<1.00$

\section{RESULTS AND DISCUSSION}

\section{Validation of the Measured Droplet Diameter}

The droplet diameter was measured online with an installed camera and with the help of software-based image analysis. This method was validated using a gravimetric measurement. A precursor solution with a concentration of $1.0 \mathrm{~g}$ copper (II) nitrate hemi(pentahydrate) in $10 \mathrm{~mL}$ ethylene glycol was aliquoted with the dosing head of the droplet generator into a previously balanced vial for 5299 seconds with a frequency of $1000 \mathrm{~Hz}$. The measured density of the precursor solution was $1.17 \mathrm{~g} \mathrm{~cm}^{-3}$. A total of $0.41 \mathrm{~g}$ of the solution was metered, which corresponded to a diameter of 50.2 microns, assuming ideal spherical shape of the individual droplets. There was no difference in the determination of the diameter between image analysis and gravimetry.

\section{Preliminary Tests: Finding a Suitable Precursor Solution}

The preliminary tests were performed with the dosing head from microdrop Technologies (Model MD-K-150020) that was designed for the use of aqueous solutions. In a first experiment, a sodium chloride-containing precursor solution was dosed into a laboratory torch burner, which resulted in several problems. Due to the waste heat produced by the burner, turbulent flows occurred at the front of the flame, which dispersed most of the generated droplets, and the pyrolysis process could not proceed quantitatively. Although the desired $\mathrm{NaCl}$ nanoparticles were formed, the generation process was not reproducible. Also, due to the waste heat of the burner, dosing the droplets vertically from above could not be performed. In the meantime, the dosing head was installed horizontally, which led to problems in handling the precursor solutions, e.g., formation of very large, adhering drops at the outlet of the dosing head. Another waste heat-related problem was the slow heating of the dosing head. When the temperature increased above $35^{\circ} \mathrm{C}$, no more droplets could be generated due to bumping of the precursor solution into the dosing capillary.

In a next step, another type of dosing head was used (Model MD-K-140-020) that was developed by the same company for the use of highly viscous substances and was thus optimally suitable for ethylene glycol. In addition, the dosing head was equipped with an internal heater, with which the precursor solutions could be heated up to approx. $100^{\circ} \mathrm{C}$. However, the choice of a high-viscosity solvent severely restricted the suitability of metal salts as precursor materials. Thus, the results showed that zinc acetate dihydrate, a precursor of zinc oxide nanoparticles, dissolves in ethylene glycol, but the solution was not stable enough and hydrolyzed within $24 \mathrm{~h}$ to form an ester. Such reactions are known, for example, the hydrolysis reactions of ethylene glycol in acetic acid were described in detail by Schmid et al. (2008). At the same time, a white precipitate of zinc hydroxide was formed, which no longer allowed droplet formation and was challenging to get rid of from the metering capillary. Therefore, zinc acetate was not suitable, and another solvent system was tested.

A mixture of hexadecane with octamethylcyclotetrasiloxane was used, which releases silica upon pyrolysis. This precursor solution was highly flammable and the flame propagated along the juxtaposed droplets towards the dosing head. In addition, the hexadecane severely damaged the sealing material of the dosing head within a few days. Therefore, ethylene glycol was used once more, this time with the salt copper (II) nitrate hemi(pentahydrate). The results indicated that this precursor solution was not subject to hydrolysis and could be stored indefinitely at room temperature, and was thus assumed to be able to release nano-sized, stable, non-hygroscopic copper (II) oxide particles. All further experiments in this study were carried out with three different concentrations of ethylene glycol-copper (II) nitrate solutions (see "Methods"). Compared to a laboratory burner, the flame generator had the advantage that the hydrogen-oxygen flame leaves the device horizontally rather than vertically. Thus, a large part of the waste heat of the burner dissipated in the lateral direction. The free fall distance $(7 \mathrm{~cm})$ of the produced droplets was sufficient to prevent the dosing head from becoming hotter than $50^{\circ} \mathrm{C}$.

In summary, it can be noted that the choice of a suitable solvent fell on ethylene glycol. The dosing head used was specially developed for this substance and made it possible to heat this liquid in the dosing capillary, in contrast to water. A suitable precursor was copper (II) nitrate, since it dissolved in ethylene glycol and did not react with it. Ethylene glycol is unsuitable for many other metal salts due to insolubility or side reactions, which limits its use as a solvent.

\section{Pyrolysis Efficiency}

The pyrolysis efficiency was not determined by weight 
measurements of the process. However, it can be assumed that this should be close to $100 \%$, since the very small precursor droplets are completely immersed in the relatively large flame cone (length: $\sim 3 \mathrm{~cm}$; diameter: $1.5 \mathrm{~cm}$ ) of the flame generator. Upon immersion of the droplets in the flame cone, the typical green color of the flame caused by copper could be observed. Only the upper surface of the flame, however, was affected by the discoloration, an indication that no components of the unpyrolyzed precursor solution could penetrate to the lower flame region or even outside the flame.

\section{SMPS Measurement Results}

Fig. 2 shows the resulting particle size distributions by pyrolysis using three different precursor solutions. Each graph contains seven distributions recorded at fixed frequencies, and each distribution represents an average curve of seven individual measurements. It can clearly be seen that the individual measurement curves differ significantly between two adjacent frequencies.

Fig. 3 illustrates the relationship between the pyrolysis of the different precursor solutions and the particle number concentration or mobility diameter at different generator frequencies.

As illustrated in Figs. 2-3, the higher the generator frequency, the larger the particle number concentration observed. The mode size also increased with increasing frequency. These findings confirmed processes that were previously reported (Hinds, 1999). If the pyrolysis processes of the three different precursor solutions were compared with one another, an increase in the number of particles, as well as an increase in the mobility diameter could be observed with increasing precursor concentration. The relationship between precursor concentration and particle number concentration or mobility diameter was nearly linear under all experimental conditions tested.

The reproducibility of the pyrolysis process was investigated in further experiments, by examining concentration of the particle number and the mobility diameter over seven days using the precursor with the concentration of $1.0 \mathrm{~g}$ of copper (II) nitrate in $10 \mathrm{~mL}$ of ethylene glycol at the frequencies $50 \mathrm{~Hz}$ and $250 \mathrm{~Hz}$. Each measurement point represented an average of seven individual measurements. The results are illustrated in Fig. 4.

The averaged particle number concentration at $50 \mathrm{~Hz}$ was $0.43 \times 10^{6} \mathrm{P} \mathrm{cm}^{-3}( \pm 9.9 \%)$ and at $250 \mathrm{~Hz} 1.32 \times 10^{6} \mathrm{P} \mathrm{cm}^{-3}$ $( \pm 6.5 \%)$. The averaged mode size at $50 \mathrm{~Hz}$ was $8.9 \mathrm{~nm}$ $( \pm 3.9 \%)$ and $10.2 \mathrm{~nm}( \pm 4.2 \%)$ at $250 \mathrm{~Hz}$.

Fig. 5 shows three different size distributions of nanoparticles under different experimental conditions using pure ethylene glycol which were determined under the following experimental conditions: flame generator on, droplet generator on; flame generator on, droplet generator off; and flame generator off, droplet generator off. The highest particle number concentration was found with generator on, droplet generator on, which is probably due to the fact that impurities from previous experiments were still present in the generator system, despite repeated flushing of the droplet generator with pure ethylene glycol. After stopping the droplet generator while still running the flame generator, a clear decrease in the particle number concentration could be demonstrated. However, it was not zero, indicating that the flame generator on its own produced a small amount of nanoparticles. Only when both generators were turned off, the particle number concentration went to almost zero. The measurement results under this condition reflected the particle background of the air conditioning technology, which was also not at zero since our exposure laboratory is not set up as a clean room (Monsé et al., 2012). The highest particle number concentration with pure ethylene glycol was $3.0 \times 10^{3} \mathrm{P} \mathrm{cm}^{-3}$, which was small compared to $0.03 \times 10^{6} \mathrm{P} \mathrm{cm}^{-3}$ achieved using the precursor with the lowest copper concentration and at the lowest frequency of $10 \mathrm{~Hz}$. The measured particle number concentration of pure ethylene glycol was at least an order of magnitude smaller and can therefore be neglected.

\section{SEM Image}

Fig. 6 shows an SEM image of collected nanoparticles, sampled with the NAS device onto a TEM grid with a flow rate of $1 \mathrm{~L} \mathrm{~min}^{-1}$. The magnification factor was 45,000 times, the concentration of the precursor solution was $1.0 \mathrm{~g}$ copper (II) nitrate in $10 \mathrm{~mL}$ ethylene glycol, and the droplet generator was set to $500 \mathrm{~Hz}$. The image shows the presence of single primary particles, and no aggregates or agglomerates were detected. Further SEM images under other conditions were not recorded.

The image analysis performed on several of the SEM and STEM images confirmed that the median particle diameter of $16 \mathrm{~nm}$ as measured on the SEM images agreed well with the SMPS measurements $(12 \mathrm{~nm})$. The difference between the two measurements of $16 \mathrm{~nm}$ and $12 \mathrm{~nm}$ may be attributed to an over estimation of the particle diameter by using the $\mathrm{S}(\mathrm{T}) \mathrm{EM}$ images.

\section{Fitted Particle Size Distributions}

The measured particle size distributions were fitted to log-normal distribution $f(d)$, where $d$ is expressed as two parameters $\sigma(\sigma>0)$ and $\mu$. The distribution parameter $\Phi$ is mainly a function of the applied droplet frequency, $f$, and can be expressed as the function $\Phi(f)=A+B f+C f^{2}$ with coefficients $A=0.431, B=3.469 \mathrm{e}-5$, and $C=-2.82 \mathrm{e}-7$ with $\mathrm{p}<0.05$ (Fig. 7).

The distribution parameter, $\mu$, depends on both the applied droplet frequency, $f$, and the precursor concentrations and can be approximated by a planar hypersurface described by $\mu(f, c)=A+B f+C c+D f c$ with coefficients $A=2.1351$, $B=4.9022, C=1.8501$, and $D=1.4364$, with $\mathrm{p}<0.07$ (Fig. 8).

A major result is the mobility particle diameter $d_{0}$, where the global maximum of PDF is reached. This is well described by a planar hypersurface $d_{0}(f, c)=A+B f+C c+$ $D f c$ with coefficients $A=7.2699, B=2.5177 \mathrm{e}-4, C=$ 9.5504, and $D=0.0350$ with $\mathrm{p}<0.05$ (Fig. 9).

This mathematical description allows predictions on median mobility diameters depending upon precursor concentration and set frequency of the droplet generator. 

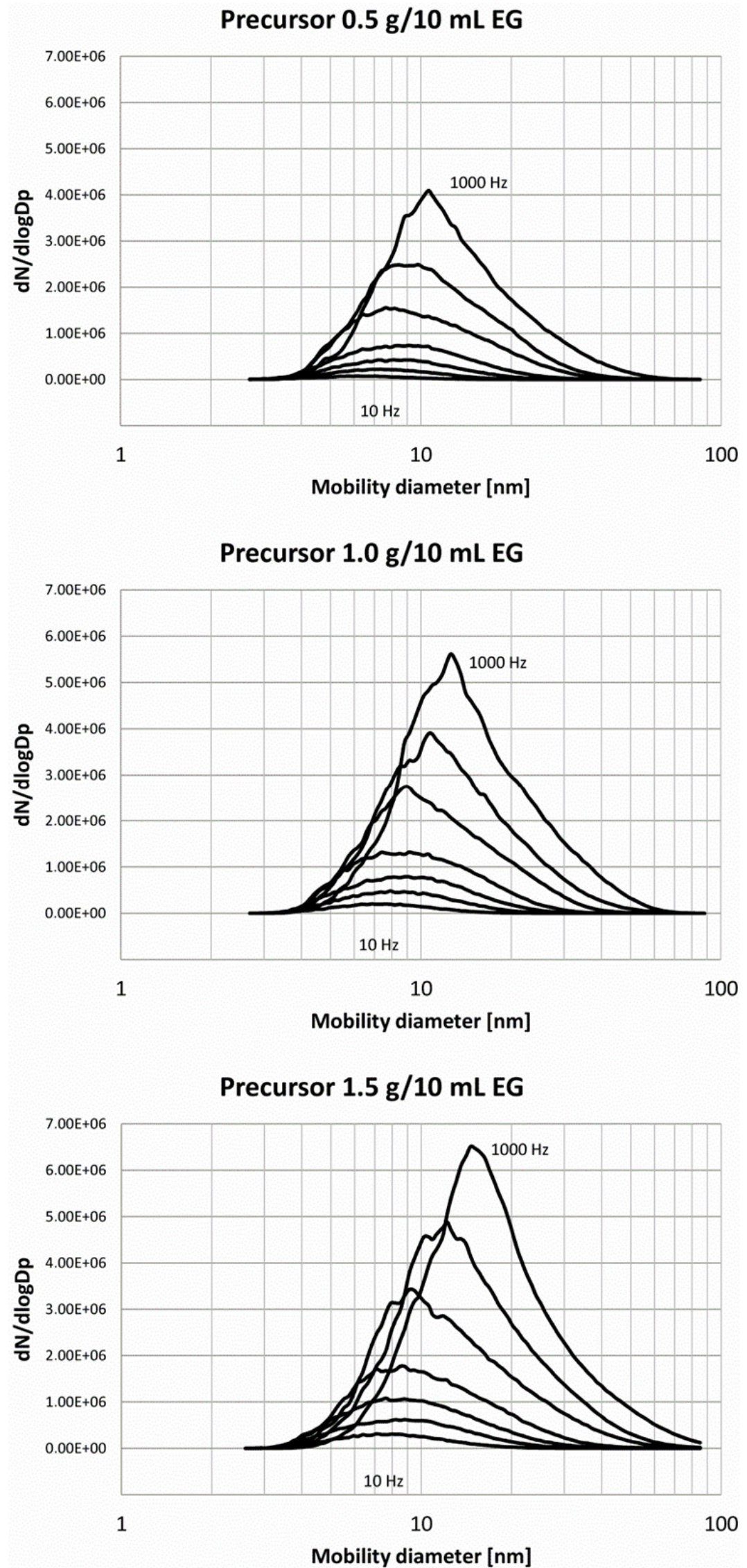

Fig. 2. Particle size distributions of three different pyrolyzed precursor solutions as a result of varying generator frequencies in the range between 10 and $1000 \mathrm{~Hz}$. 

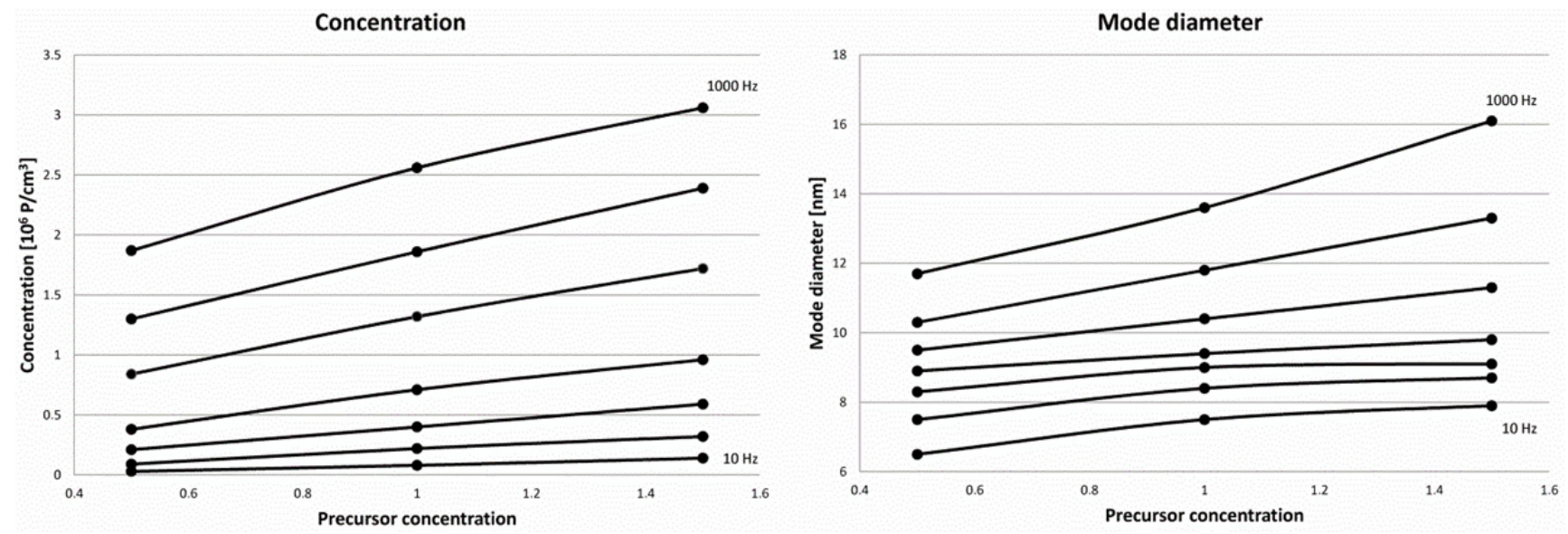

Fig. 3. Particle number concentration (left panel) and mobility particle diameter (mode size, right panel) relative to the precursor concentration and varying generator frequencies in the range of 10 to $1000 \mathrm{~Hz}$.
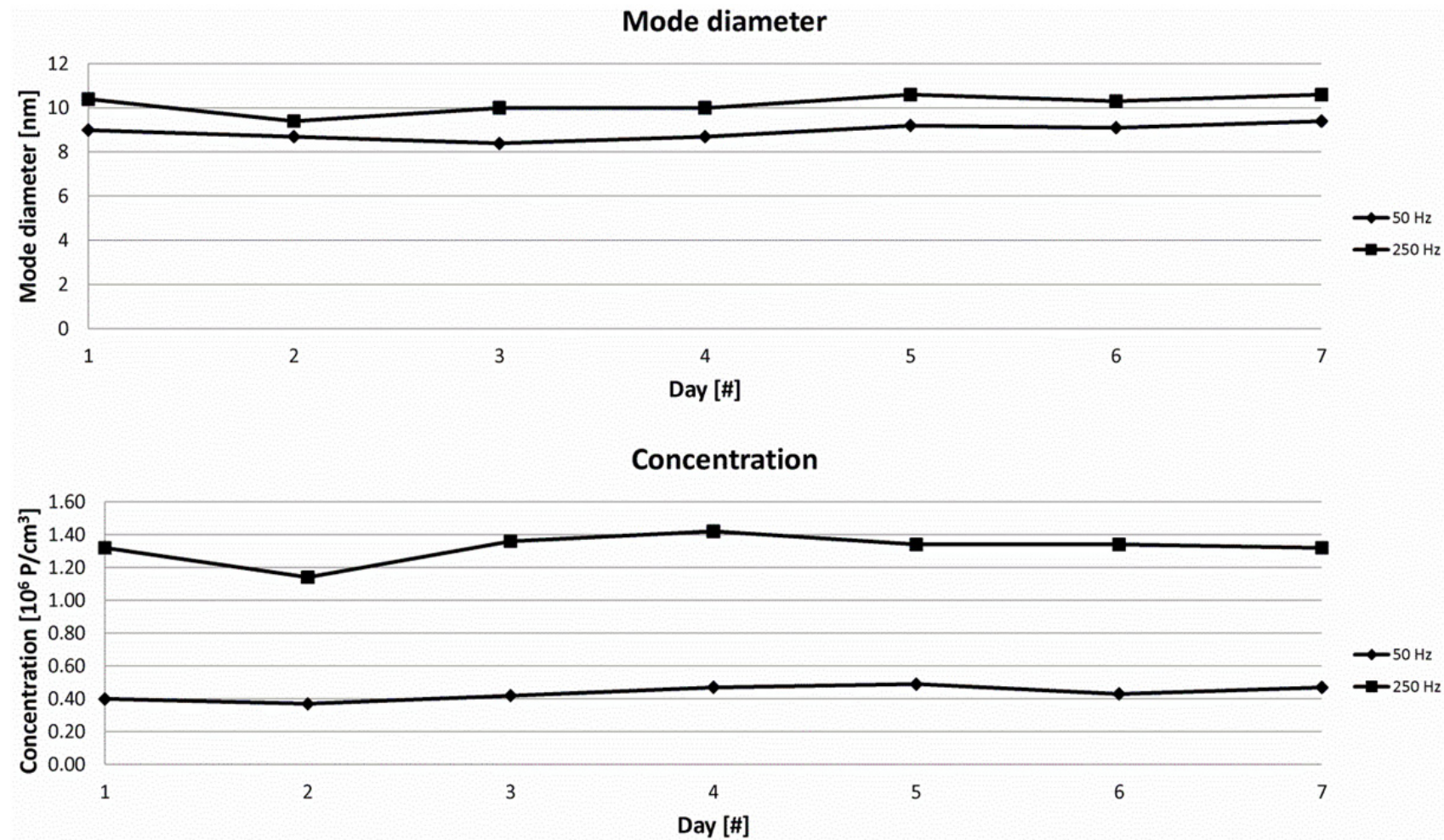

Fig. 4. Mode diameter (top panel) at 50 and $250 \mathrm{~Hz}$ and repeatability of particle number concentration (bottom panel). Precursor concentration was $1.0 \mathrm{~g}$ copper (II) nitrate in $10 \mathrm{~mL}$ ethylene glycol.

\section{Comparison to Existing Systems}

A whole series of new ideas were used when developing our system. The advantages over existing methods are that the precursor solution can be metered into specifically adjustable individual droplets. Furthermore, the droplets are monodisperse and the droplet generator is independent of room temperature fluctuations by deliberate heating of the precursor solution. Otherwise, temperature fluctuations at the same setting conditions of the generator can strongly influence the size of the droplets, which we found in preliminary tests (data not shown). In addition, the individual droplets can be observed with a camera system for quality assurance reasons and to guarantee that the droplet diameter is always identical. If necessary, the diameter can be readjusted. When solution aerosol droplets are used by generation with atomizing gas (Mädler et al., 2002; Tani et al., 2002), a micro-jet atomization technique (Abram et al., 2018), or ultrasonic atomization (Pingali et al., 2005), the precursor droplets are not monodisperse and cannot be selectively generated individually. The geometric structure of the flight path of the single droplets up to the flame cone prevents turbulent flow. This avoids contacts of both the precursor droplets and the generated nanoparticles with the surfaces of the apparatus. Otherwise, impaction or diffusion 


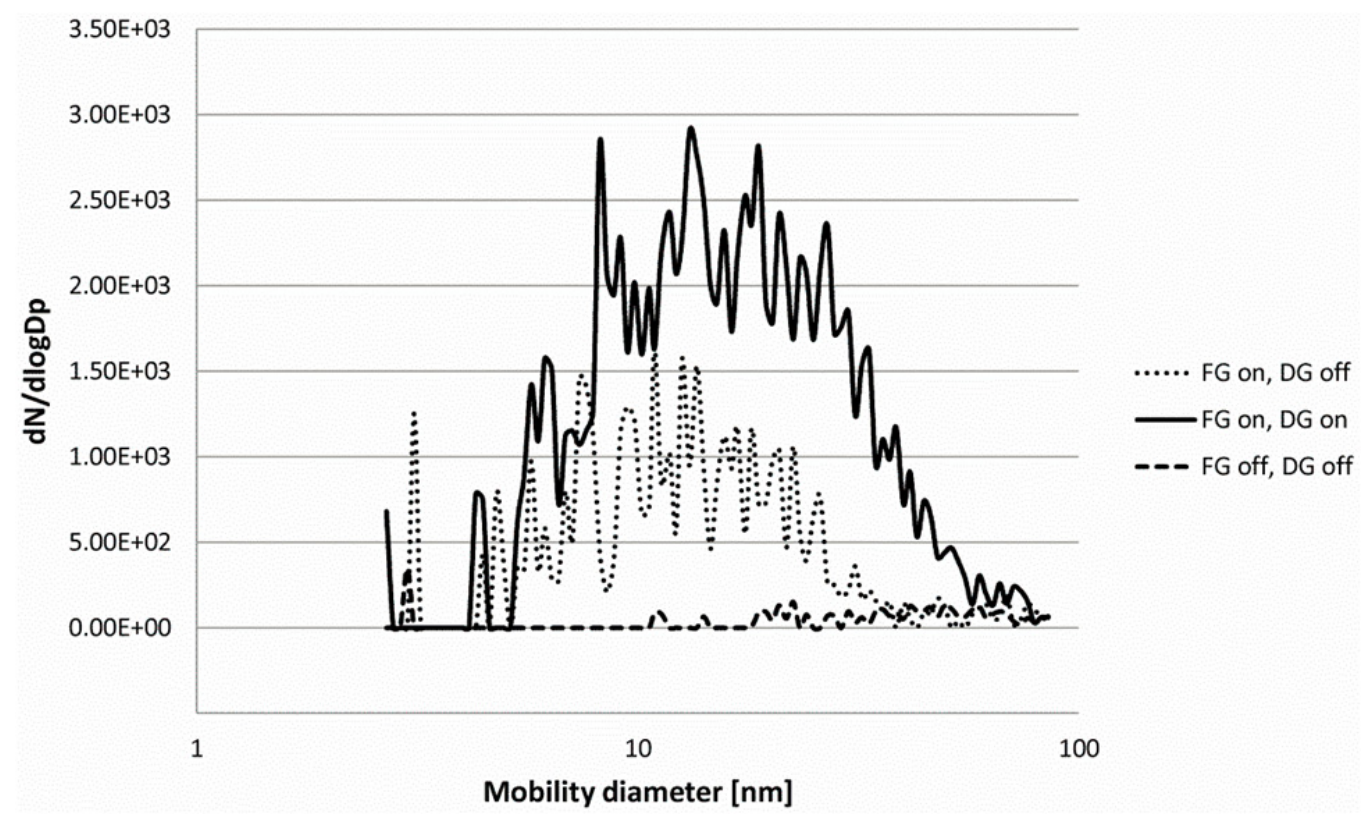

Fig. 5. Size distributions of nanoparticles using pure ethylene glycol in different experimental setups. FG: Flame generator, DG: droplet generator.

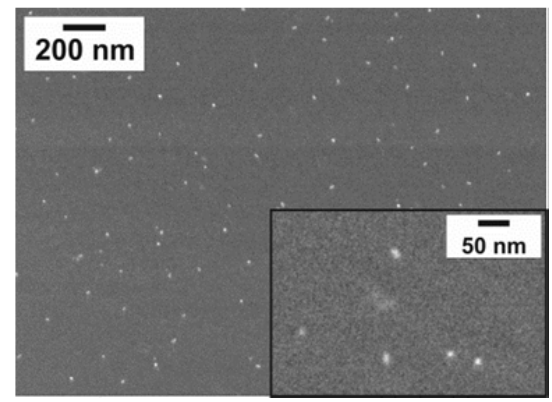

Fig. 6. SEM image of collected copper (II) oxide nanoparticles.

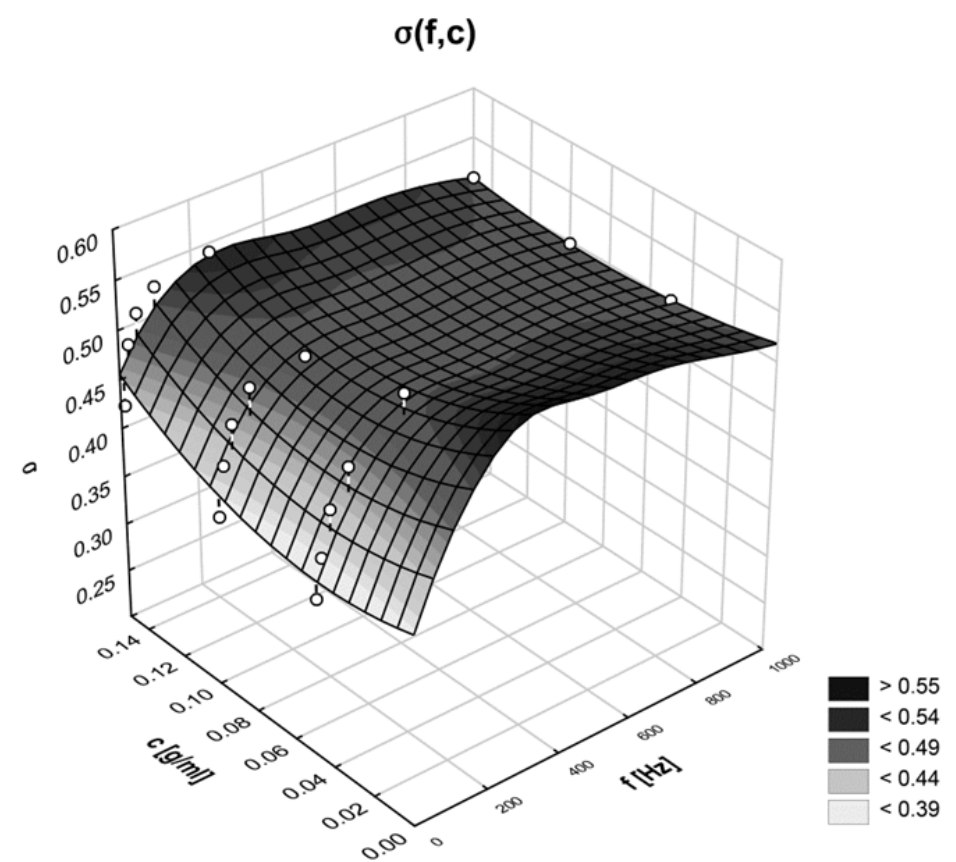

Fig. 7. Distribution parameter $\sigma$ in relation to (or dependent upon) the precursor concentration c and frequency f. 


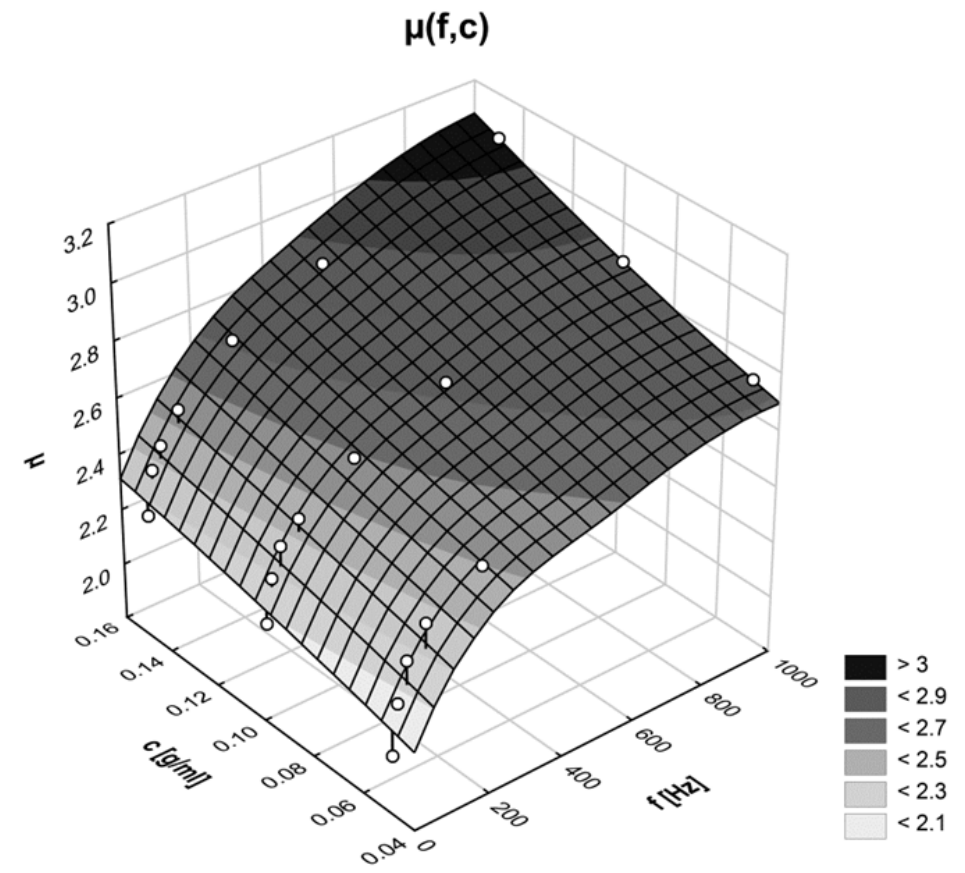

Fig. 8. Distribution parameter, $\mu$ in relation to precursor concentration $\mathrm{c}$ and frequency $\mathrm{f}$.

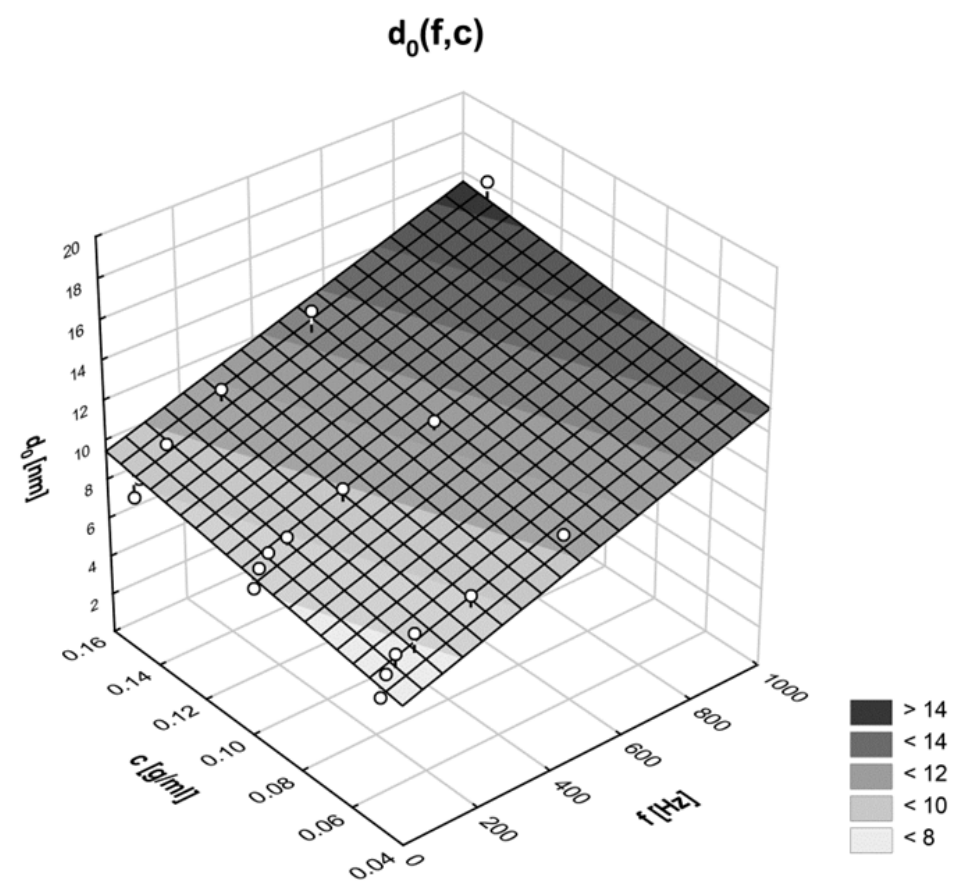

Fig. 9. Mobility particle diameter $\mathrm{d}_{0}$, where the global maximum of PDF is reached dependent upon the precursor concentration $\mathrm{c}$ and frequency $\mathrm{f}$.

may cause unreproducible particle losses, especially in systems using furnace tubes (Adachi et al., 2003; Miettinen et al., 2009).

\section{CONCLUSION}

The combination of a droplet generator and a flame generator, together with a precursor solution consisting of ethylene glycol and copper (II) nitrate, allowed us to generate nanoscale particles at relatively low number concentrations. The precursor solution was indefinitely stable at room temperature. A nearly linear relationship between the number concentration and the mobility diameter as a function of the precursor concentration and the metering frequency was observed. A mathematical description of the physical effects was also established, which enabled the prediction of the mobility diameter based on the precursor concentration and the droplet frequency. The system was 
stable and reproducible, with the resulting errors falling within the margins specified by the SMPS manufacturer. The development of this new particle source ensures that the technical center of the IGF can expand round robin testing to include the validation and comparison of particle measurement instruments.

\section{REFERENCES}

Abram, C., Mezhericher, M., Beyrau, F., Stone, H.A. and Ju, Y. (2018). Flame synthesis of nanophosphors using sub-micron aerosols. Proc. Combust. Inst., in Press.

Adachi, M., Tsukui, S. and Okuyama, K. (2003). Nanoparticle formation mechanism in CVD reactor with ionization of source vapor. J. Nanopart. Res. 5: 31-37.

Asbach, C., Kaminski, H., Fissan, H., Monz, C., Dahmann, D., Mülhopt, S., Paur, H.R., Kiesling, H.J., Herrmann, F., Voetz, M. and Kuhlbusch, T.A.J. (2009). Comparison of four mobility particle sizers with different time resolution for stationary exposure measurements. $J$. Nanopart. Res. 11: 1593-1609.

Asbach, C., Kaminski, H., von Barany, D., Kuhlbusch, T.A.J., Monz, C., Dziurowitz, N., Pelzer, J., Vossen, K., Berlin, K., Dietrich, S., Götz, U., Kiesling, H.J., Schierl, R. and Dahmann, D. (2012). Comparability of portable nanoparticle exposure monitors. Ann. Occup. Hyg. 56: 606-621.

Borovinskaya, O., Hattendorf, B., Tanner, M., Gschwind, S. and Günther, D. (2013). A prototype of a new inductively coupled plasma time-of-flight mass spectrometer providing temporally resolved, multielement detection of short signals generated by single particles and droplets. J. Anal. At. Spectrom. 28: 226233.

Dahmann, D., Riediger, G., Schletter, J., Wiedensohler, A., Carli, S., Graff, A., Grosser, M., Hojgr, M., Horn, H.G., Matter, U., Monz, C., Mosimann, T., Stein, H., Wehner, B. and Wieser, U. (2001). Intercomparison of mobility particle sizers (MPS). Gefahrstoffe Reinhalt. Luft 61: 423-427.

Dixkens, J. and Fissan, H. (1999). Development of an electrostatic precipitator for off-line particle analysis. Aerosol Sci. Technol. 30: 438-453.

Fonseca, A.S., Viana, M., Pérez, N., Alastuey, A., Querol, X., Kaminski, H., Todea, A.M., Monz, C. and Asbach, C. (2016). Intercomparison of a portable and two stationary mobility particle sizers for nanoscale aerosol measurements. Aerosol Sci. Technol. 50: 653-668.

Franze, B., Strenge, I. and Engelhard, C. (2012). Single particle inductively coupled plasma mass spectrometry: Evaluation of three different pneumatic and piezo-based sample introduction systems for the characterization of silver nanoparticles. J. Anal. At. Spectrom. 27: 10741083.

Geier, M. and Parker, T. (2013). Electrospray flame synthesis of yttria-stabilized zirconia Nanoparticles. Ind. Eng. Chem. Res. 52: 16842-16850.

Giesen, Y., Hagemann, C., Nürnberger, F., Maybaum, B., Breuer, D., Monz, C. and Monsé, C. (2016a).
Reproduzierbare Beaufschlagung von Membranfiltern mit luftgetragenen Metallen zur Durchführung von Ringversuchen. Gefahrstoffe Reinhalt. Luft 76: 415-421.

Giesen, Y., Raschig, F., Lamm, N. and Breuer, D. (2016b). Etablierung eines Mikrodosierverfahrens zur Herstellung von Referenzmaterialien. Gefahrstoffe Reinhalt. Luft 76: 26-30.

Groh, S., Garcia, C.C., Murtazin, A., Horvatic, V. and Niemax, K. (2009). Local effects of atomizing analyte droplets on the plasma parameters of the inductively coupled plasma. Spectrochim. Acta B 64: 247-254.

Gschwind, S., Flamigni, L., Koch, J., Borovinskaya, O., Groh, S., Niemax, K. and Günther, D. (2011). Capabilities of inductively coupled plasma mass spectrometry for the detection of nanoparticles carried by monodisperse microdroplets. J. Anal. At. Spectrom. 26: 1166-1174.

Hinds, WC. (1999). Aerosol technology: Properties, behavior and measurement of airborne particles. John Wiley \& Sons Inc., New York, pp. 260-277.

Kaminski, H., Rath, S., Götz, U., Sprenger, M., Wels, D., Polloczek, V., Bachmann, V., Dziurowitz, N., Kiesling, H.J., Schwiegelshohn, A., Monz, C., Dahmann, D., Kuhlbusch, T.A.J. and Asbach, C. (2013). Comparability of mobility particle sizers and diffusion chargers. $J$. Aerosol Sci. 57: 156-178.

Mädler, L., Kammler, H.K., Mueller, R. and Pratsinis, S.E. (2002). Controlled synthesis of nanostructured particles by flame spray pyrolysis. J. Aerosol Sci. 33: 369-389.

Miettinen, M., Riikonen, J., Tapper, U., Backman, U., Joutsensaari, J., Auvinen, A., Lehto, V.P. and Jokiniemi, J. (2009). Development of a highly controlled gasphase nanoparticle generator for inhalation exposure studies. Hum. Exp. Toxicol. 28: 413-419.

Monsé, C., Sucker, K., van Thriel, C., Broding, H. C., Jettkant, B., Berresheim, H., Wiethege, T., Käfferlein, H. U., Merget, R., Bünger, J. and Brüning, T. (2012). Considerations for the design and technical setup of a human whole-body exposure chamber. Inhalation Toxicol. 24: 99-108.

Monsé, C., Monz, C., Dahmann, D., Asbach, C., Stahlmecke, B., Lichtenstein, N., Buchwald, K.E., Merget, R., Bünger, J. and Brüning, T. (2014). Development and evaluation of a nanoparticle generator for human inhalation studies with airborne zinc oxide. Aerosol Sci. Technol. 48: 418-426.

Monsé, C., Hagemeyer, O., Raulf, M., Jettkant, B., van Kampen, V., Kendzia, B., Gering, V., Kappert, G., Weiss, T., Ulrich, N., Marek, E.M., Bünger, J., Brüning, T. and Merget, R. (2018). Concentration-dependent systemic response after inhalation of nano-sized zinc oxide particles in human volunteers. Part. Fibre Toxicol. 15: 8.

Pillar, F., Kahl, A., Brüning, T. and Monsé, C. (2016). Validierungsuntersuchungen eines Berechnungsmodells zur Ausbreitung von Gefahrstoffen. Gefahrstoffe Reinhalt. Luft 76: 19-25.

Pingali, K.C., Rockstraw, D.A. and Deng, S. (2005). Silver nanoparticles from ultrasonic spray pyrolysis of aqueous silver nitrate. Aerosol Sci. Technol. 39: 1010-1014.

Raschick, F., Monsé, C., Gusbeth, K., Maybaum, B., 
Giesen, Y., Breuer, D. and Monz, C. (2016). Ringversuche für innerbetriebliche und außerbetriebliche Messstellen an der Prüfgasstrecke des Instituts für Arbeitsschutz der Deutschen Gesetzlichen Unfallversicherung (IFA). Gefahrstoffe Reinhalt. Luft 76: 78-84.

Schmid, B., Döker, M. and Gmehling, J. (2008). Esterification of ethylene glycol with acetic acid catalyzed by Amberlyst 36. Ind. Eng. Chem. Res. 47: 698-703.

Tani, T., Mädler, L. and Pratsinis, S.E. (2002). Homogeneous $\mathrm{ZnO}$ nanoparticles by flame spray pyrolysis. J. Nanopart. Res. 4: 337-343.

Teoh, W.Y., Amal, R. and Mädler, L. (2010). Flame spray pyrolysis: An enabling technology for nanoparticles design and fabrication. Nanoscale 2: 1324-1347.

Wang, Y.F., Yen, H.Y., Tsai, Y.I., Chen, H.M. and Tsai, C.H. (2013). Rapid thermal synthesis of nano titanium dioxide powders using a plasma torch. Aerosol Air Qual. Res. 13: 1313-1320.

Received for review, June 15, 2018 Revised, September 13, 2018 Accepted, November 7, 2018 